\title{
PERAN PENDIDIKAN TINGGI DALAM MENGEMBANGKAN SENI GRAFIS DI INDONESIA
}

\author{
NUNING YANTI DAMAYANTI \\ Received: 20 Oktober 2019; Accepted: 26 Oktober 2019; Published: 5 November 2019
}

Ed. 2019; 3 (1): $046-051$

\begin{abstract}
Conventional Graphic Art is understood by academics through the history of its development. The Chinese nation is thought to have started the tradition of print as the forerunner of graphic art in its 'primitive' era, while the Romans began etching-glass techniques for portraying gladiators. Furthermore, the Japanese in the 8th century had begun their first authentic print by tracing and printing Buddhist faces. When the Europeans used it as a printing technique as a medium for artistic expression, the word "printmaking" emerged, which was later adopted by the field of art until now. Later the graphic arts were increasingly used to reproduce various human needs. In early 1900 the Dutch introduced the technique of Graphic Printing in education at the Bandung Technical College is now the Bandung Institute of Technology. History and development of Indonesian Graphic Arts in history began at Institute of Technology Bandung (ITB) as the first academic provider of formal education in the Department of Fine Arts, then now a Faculty of Fine Arts and Design (FSRD) of ITB. Conventional Graphic Printing Techniques become one of the main areas of interest, the Graphic Arts Studio of the Fine Arts Department, then became the Fine Art Study Program and the Graphic Art Printing Technique until now is still the main area of interest and subject matter in the curriculum of the FSRD ITB Fine Arts Study Program.
\end{abstract}

Keyword: print graphics, printmaking, graphic arts, Institute of Technology Bandung (ITB).

\section{PENDAHULUAN}

\section{Seni Cetak Grafis/Printmaking Dunia}

Di Barat sendiri sebelum era percetakan, print making pada awalnya tidak termasuk pertimbangan dalam kategori karya seni, hanya dianggap sebagai media komunikasi untuk penyebaran berita dalam kegiatan-kegiatan keagamaan dan kegiatan-kegiatan sosial kemasyarakatan. Barulah sekitar abad-18 seni grafis/printmaking di Eropa mulai diperhitungkan dalam kategori karya seni, dengan pengakuan orisinalitas dari hasil cetakannya. Originalitas ini diakui dengan banyaknya seniman memproduksi cetakan karya seni dengan edisi terbatas dan dengan menandatangi tiap cetakan berikut menuliskan informasi teknik pada bagian bawah karyanya. Cetakan gambar yang sekarang biasanya dilakukan di atas kertas, pada awalnya di Eropa sebenarnya dicetakan di atas kain tekstil. Dalam perkembangannya Seni Grafis juga menyebabkan berkembangnya pembuatan kertas di Eropa. Cetakan di atas kertas dipengaruhi tradisi Timur Jauh sekitar Abad-6. Kertas sendiri berawal dari budaya china diperkirakan sudah mulai ada jejaknya sekitar 100 tahun sebelum masehi. Orang Eropa belajar membuat kertas dari orang Islam di Jativa Spanyol, sedangkan 
orang Islam mempelajarinya dari orang China yang menjadi tawanan perang masa lalu di Uzbekistan.

Teknik cetak yang pertamakali ditemukan adalah tehnik cukil kayu/woodcut memakai medium kayu sebagai matriks atau plat acuannya. Teknik pertama ini yang digunakan dalam tradisi seni grafis sebelum ditemukannya teknik-teknik lain. Cukil kayu ini telah lama digunakan untuk ornamen tekstil, kemudian juga diterapkan dalam kitab berisi doa sang Budha di China paruh awal abad-5. Kitab tersebut bernama diamond sutra, berisi cetakan cukil kayu dan tulisan. Selanjutnya teknik mencetak ini memasuki wilayah Eropa melalui negara Jerman tahun 1400, lalu mengalami masa perkembangan. Nama Gutenberg dikenal sebagai penemu mesin cetak pertama yang berhasil menciptakan metal letter dan teknik linocut yang dapat menghasilkan gambar dan teks tulisan secara bersamaan. Contoh Karya Grafis Eropa Klasik.
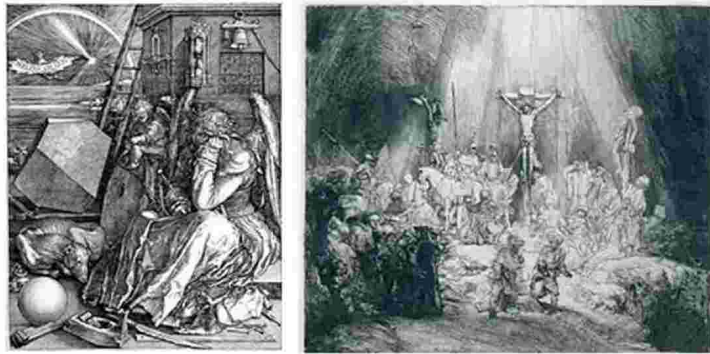

Kiri ke Kanan Karya Albrecht Duerer dan Karya Rembrant

https://id.wikipedia.org/wiki/Seni_grafis

Kemudian Selanjutnya berturut turut ditemukan proses cetak dalam/intaglio tahun 1446 yang menyebar ke Italia dan beberapa kota di Eropa. Cetak dalam ini menggunakan acuannya dari plat tembaga. Kemudian ditemukan tehnik cetak datar merupakan perkembangan selanjutnya dengan menggunakan batu lithography sebagai acuan yang ditemukan oleh Aloys Senefelder tahun 1796 di kota Munchen, dalam waktu yang singkat temuan ini langsung menyebar ke Eropa yang di pakai untuk ilustrasi dan promosi produk iklan. Teknik cetak saring/silk screen berasal dari daratan China yang kemudian berkembang di Eropa abad ke 15, menandai perkembangan teknik cetak saring adalah setelah perang dunia ke-2. Teknik ini berkembang luas di Amerika setelah dikembangkan oleh seniman Amerika Andi Warhol dan menjadi salah satu media pengusung gaya seni pop art.
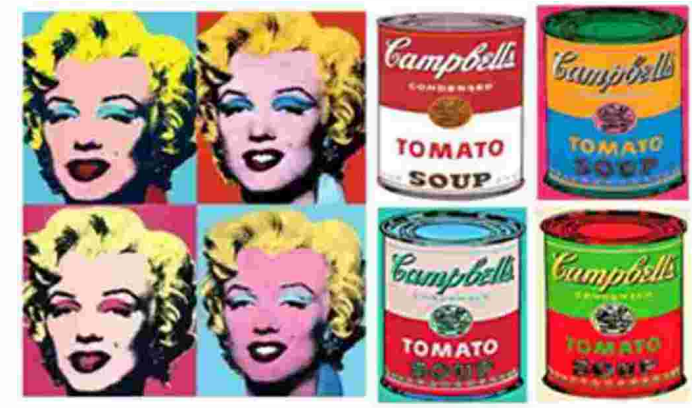

Karya Seni Grafis Pop Art : Andi Wahrhol; Marilyn Monroe, Campbells Art.with.mr sleuer.com

Penemuan medium-medium yang berbeda dalam perkembangan teknik cetak grafis dari yang paling sederhana sampai melalui proses kimiawai yang rumit menimbulkan perbedaan dalam peralatan, bahan, dan proses pengerjaan juga memunculkan perbedaan karakteristk gambar yang dihasilkan. Sifat berkarya seni melalui medium grafis menimbulkan tantangan tertentu bagai para seniman. Tantangan yang utama biasanya timbul dari proses berkarya yang tidak langsung jadi, memerlukan tahapantahapan proses pembuatan yang harus dilalui. Proses itu dimulai dari pembuatan sketsa gambar, pemindahan ke plat acuan sampai ke proses reproduksi. Tahapan-tahapan dalam proses pembuatan karya tersebut justru membuka peluang-peluang bagi seniman untuk bereksplorasi, berkreasi dan bereksperimen dengan pemanfaatan sifat dan cara kerja media.

\section{Awal Seni Cetak Grafis/Printmaking di Indonesia}

Seni grafis Indonesia, bersamaan dengan cabang seni lainnya hadir di Indonesia tidak bisa lepas 
dari masa Kolonialisme. Perkembangan seni grafis di Indonesia sekarang adalah pengaruh dari perkembangan sejarah printmaking di Barat. Pada masa itu pemerintah Belanda perlu untuk merekam dan mendokumentasi berbagai hal yang berkaitan dengan lingkungan geografi, kehidupan manusia Indonesia juga flora, fauna dan lain sebagainya. Sejumlah pakar, seniman dan tukang gambar ditugaskan melakukan studi dan pendataan dalam wujud visual diberbagai bidang pengetahuan. Termasuk juga bidang seni rupa, dimana tehnik yang dipergunakan untuk merekam gambaran tentang Indonesia adalah wood Engraving dan Lithografi, tehnik yang sudah berkembang lama di Eropa. Berangkat kebutuhan tersebut lambat laun teknik cetak grafis mulai diperkenalkan secara tidak langsung kepada rakyat Indonesia melalui hasil karya cetak grafis yaitu tehnik Lithografi, Wood Engraving juga teknik Etsa. Pada awal tahun1900 Belanda membuka Universitas pertama di Indonesia yaitu Universitas Indonesia dan Sekolah Tinggi Tehnik Bandung sekarang menjadi Institut Teknologi Bandung.

Seni grafis dari awal perkembangannya diposisikan sebagai pendamping karya-karya lukisan dan patung dan juga sebagai proses berkarya sampingan yang dilakukan seniman. Seni grafis pada awalnya sebatas pelengkap muncul di pameran seni bersanding karya lukisan dan patung. Meskipun demikian, seni grafis pernah dianggap sebagai cabang seni yang ikut berjasa bagi kehidupan kenegaraan Indonesia, dengan mengirim karya-karya grafis ke luar negri pada perayaan tahun pertama kemerdekaan Indonesia, 1946, sebagai upaya memberi kesan bahwa Indonesia adalah negara yang berbudaya, meski baru satu tahun merdeka. Perkembangan seni grafis pada awal kemerdekaan Indonesia dinilai sebagai tenggat waktu eksplorasi para seniman untuk mendalami dan menyerap ilmu menangani teknik cetak grafis. Terlihat pada beberapa karya grafis Mochtar Apin, Sudjana
Kerton, dan Poppo Iskandar yang menekuni studi visual menggunakan teknik cetak, baik dalam pendekatan naturalis maupun abstrak yang merebak luas dan kemudian diteruskan oleh seniman-seniman generasi berikutnya secara pasti terus meluas dan menglobal.

Pendidikan seni grafis secara formal dimulai sekitar tahun 1965 di Seni Rupa ITB, yang sejak itu mulai melaksanakan pengajaran seni grafis secara sistematis. Dimana dibawah Fakultas Tehnik Sipil, ada Departemen Seni Murni yang kemudian membesar menjadi Fakultas Seni Rupa dan Desain pertama di Indonesia yang mengembangkan berbagai minat dan teknik untuk mencapai penguasan estetik dengan berbagai fasilitas pendukung yang diperlukan oleh mahasiswa. Ketika masih lingkup Departemen Seni Murni mendapat fasilitas peralatan yang paling lengkap termasuk studio Seni Grafis. Sejarah dan perkembangan Seni Grafis Indonesia dalam sejarah dimulai di ITB sebagai penyelenggara pendidikan formal pertama secara akademis dan adanya di Jurusan Seni Murni. Teknik cetak grafis yang konvensional pada bidang minat utama Studio Seni Grafis Departemen Seni Murni FSRD ITB sampai sekarang masih merupakan pokok materi dalam kurikulum pengajaran kerja praktek Studio Grafis. Salah satu teknik grafis yang diajarkan yaitu cetak tinggi/cukil kayu (Reliefprint), Cetak dalam (Intaglio), Cetak datar (Lithografi), Cetak saring (Serigraphy).

Barulah pada tahun 1970-1980, seni grafis mulai muncul ke permukaan dengan hadir pada pameran seni grafis yang mandiri. Maka bermunculanlah pegrafis-pegrafis akademik dan para lulusannya yang kemudian bersemangat untuk memasyarakatkan disiplin seni rupa ini sambil mempromosikan ciri-cirinya yang berbeda dengan disiplin-disiplin seni rupa yang lainnya. Mulai ada program pameran 'Seni Grafis Bandung' yang menampilkan karya-karya 
Baharoedin Marasutan, Mochtar Apin, A.D. Pirous, dan Kaboel Soeadi, Haryadi Suadi, yang dipamerkan di tiga kota, yakni Bandung, Surabaya, dan Jakarta. Dua tahun setelahnya, lahirlah kelompok grafis Decenta yang beranggotakan AD. Pirous, Sunaryo, T. Sutanto, G. Siddharta, Priyanto, dan Dudi Kusnidar dari Bandung yang mendalami teknik serigrafi yang kala itu sedang berkembang didukung laju perkembangan industri garmen.

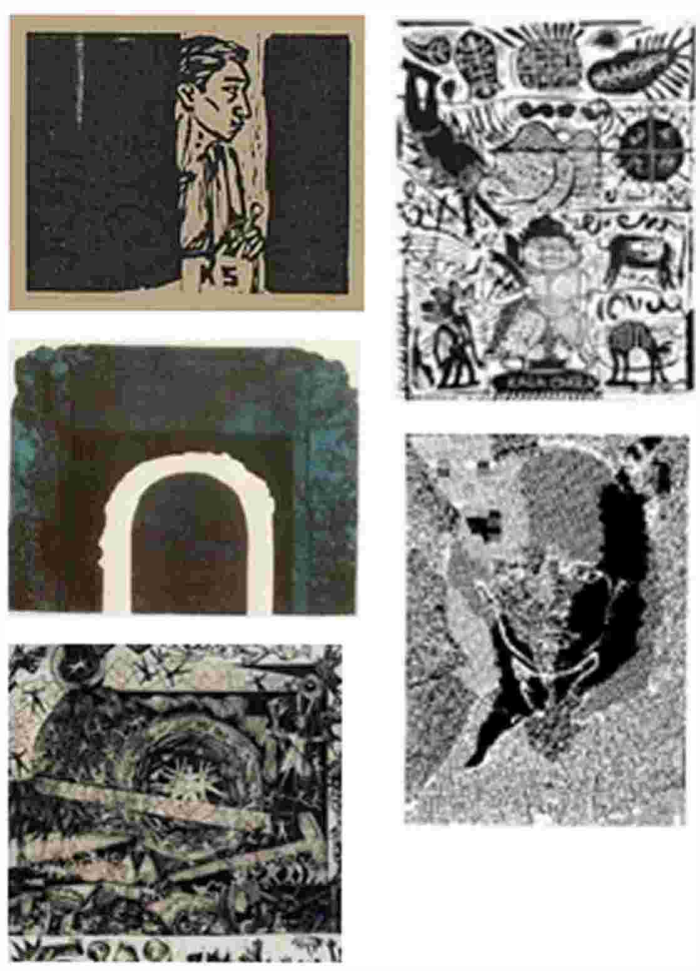

$$
\begin{gathered}
\text { Seniman Pendidik Bandung, dari Kiri kekanan } \\
\text { Karya Seni Grafis } \\
\text { Kaboel Suadi, Haryadi Suadi, } \\
\text { Setiawan Sabana, Tisnasanjaya, } \\
\text { Nuning Damayanti } \\
\text { (Repro Nuning Y Damayanti) }
\end{gathered}
$$

Khususnya pada seni grafis Bandung kecenderungan penggunaan media pun mulai terlihat, hal ini mungkin disebabkan oleh tersedianya mesin cetak dan alat pendukung lainnya dalam berkarya seni grafis ITB, yang sejak masa awalnya sudah memiliki mesin terlengkap di Indonesia melahirkan seniman yang diberi kesempatan lebih untuk mengeksplorasi teknik grafis. Pendidikan seni grafis di Bandung, memunculkan kesadaran pada akan tradisi media, dan menjadi hal yang sering dipertanyakan pada senimannya, karena keleluasaan dalam pemilihan teknik cetak yang digunakan.

Sementara di Jogja, kelangkaan mesin cetak datar dan kurang fungsionalnya mesin cetak kemudian megantarkan senimannya untuk menggeluti teknik cetak tinggi khususnya tehnik cukil kayu dan cetak saring Serigrafi/sablon, kemudian menjadi media yang diminati pendidikan di Yogya sebetulnya juga di Bandung. Hal yang menjadi pendukung berkembangnya tehnik cetak grafis adalah kemudahan dalam keberadaan media pendukungnya, hal tersebut yang menyebabkan Bandung danYogya yang memiliki visi dalam pendidikan, namun tetap memiliki kecenderungan yang berbeda dalam penyajian karyanya. Pekerja keras seniman Grafis di Yogyakarta meskipun memiliki keterbatasan mesin cetak, ternyatahalini tidak menjadi hambatan bagi para penggrafis Jogja, mereka menggeluti tehnik cukil kayu hingga mencapai penguasaan teknis yang dapat dinilai sangat baik dan menjadi karakter kuat seni grafis Yogya.

\section{Seni Grafis Kontemporer Indonesia dan Permasalahan}

Menjelang akhir 1990-an, konsepsi seni baru berkembang di Indonesia yang diberi sebutan postmodernisme membawa perubahan dan kebaruan yang kontroversi menjadi kritis pada seni rupa Indonesia, tidak terlepas juga pada seni grafis. Inovasi ide dan ekspresi yang dimiliki seiman pada karya dituangkan pada media dan material yang dianggap memperkaya wujud seni rupa Indonesia saat itu. Bermunculan seperti karya-karya performance art, instalasi, inter media dan media lainnya yang unik dan mengundang kontroversi. Pada Bienalle IX Jogja sebagian besar karyanya merayakan kehadiran potmodernisme dengan menjatuhkan pilihan 
pada instalasi. Meskipun begitu, seniman grafis tetap mencoba memadukan teknik grafis dengan media asing yang dinamai instalasi, seperti yang dilakukan Marida Nasution pada pameran 'Taman Plastik', Setiawan Sabana dengan tampilan instalasi "Rampak", kemudian Tisna Sanjaya dengan instalasinya yang berjudul 'Seni Grafis dan Sepakbola', dan beberapa seniman lainnya yang mencoba tetap menyisipkan corak seni grafis yang membentuk proses penciptaan karyanya bersanding dengan arus deras kritisisme postmodernisme.

Seni grafis kontemporer Indonesia adalah cabang seni yang dinilai amat kaya, baik secara visual mauoun ide yang dituangkan senimannya. Proses berkarya grafis kemudian mempengaruhi kecenderungan berkarya para senimannya kemudian melahirkan seniman yang memiliki pola kerja yang teratur dan pemikiran yang terstruktur. Perkembangan seni grafis kontemporer Indonesia kemudian dinilai amat berkembang dengan baik, eskplorasi teknis diaplikasikan pada media yang tidak biasa diterapkan dalam penyajian karya grafis. Dari kertas, kanvas, kayu, bahkan akrilik. Media dengan teknologi pun memberikan banyak opsi yang sangat banyak bagi seniman grafis untuk berkarya. Bahkan lebih jauh lagi, perenungan kontemplatif seniman kemudian melahirkan penyajian karya yang menggunakan teknik cetak secara filosofis. Dapat disimpulkan dari sedikit uraian diatas bahwa seni grafis Indonesia bukanlah cabang seni yang tanpa sejarah, namun dapat dipandang sebagai cabang seni yang melahirkan seniman yang memiliki kekhasan baik dalam pemikiran maupun kekaryaanya. Mampu menunujukan eksistensinya dalam memperkarya seni rupa Indonesia. Keterbatasan dan kelangkaan alat dan mesin cetaklah yang dikambing hitamkan oleh para seniman grafis bahkan menggeluti bidang yang amat jauh dari kajian seni grafis. Kekhawatiran ini memang bukanlah tanpa sebab, minimnya mesin dan alat-alat pendukung dalam membuat sebuah karya grafis seringkali meredam hasrat berkarya dan memuaskan keinginan bereksplorasi para seniman grafis. Krisis ini pun bahkan dialami oleh institusi akademi seni di Indonesia. Tercatat bahwa hanya Institut Teknologi Bandung yang mampu menyediakan mesin cetak dan alat-alat pendukung untuk teknik cetak tinggi, cetak rendah, cetak datar, dan cetak saring yang dianggap memadai.

\section{KESIMPULAN}

Pendidikan Tinggi Seni sangat berperan alam perkembangan Seni Grafis di Indonesia, para alumni pendidikan tinggi seni tersebut yang menjadi pelopor dan pejuang menyebarkan dan mengembangkan tehni cetak grafis, baik sebagai pendidik maupun sebagai seniman grafis. Tampaknya potensi seni grafis konvensional, baku dan ketat, yang kadang dianggap sebagai hambatan dalam penciptaan karya seni grafis tidak berarti harus dihindari, karena konvensi bagaimanapun juga menjadi penting sebagai pemahaman yang harus menjadi dasar ketika ingin mengembangkannya. Untuk kepentingan kreativitas dan juga untuk pengembangan apresiasi seni grafis itu sendiri, pemikiran dan langkah-langkah kreatif perlu digagas dan dieksplorasi. Keterbatasan fasilitas seni grafis bisa disiasati dengan memanfaatkan bahan maupun peralatan yang ada secara optimal. Para pegrafis dan pendidikan bidang Seni Grafis Indonesia harus mampu untuk menciptakan fasilitas yang diperlukan, dengan mengandalkan bahan dan teknologi yang tersedia, baik menyangkut kertas, tinta cetak, ataupun mesin cetak dan peralatan lainnya. Seni Grafis Indonesia harus mampu membangun sejarahnya sendiri meskipun tehnik cetak grafis ini diadopsi dari negara lain. 


\section{DAFTARPUSTAKA}

ADISASMITO, NUNING YD.

2002. Buku Seniman Buku Sebagai Obyek.

Berekspresi dalam Berkesenian, Penerbit, STISI TELKOM, hlm; 1-16.

DAMAYANTI, NUNING.

1989. Pengantar Tugas Akhir Seni Grafis, Publikasi terbatas, FSRD-ITB.

\section{SUPRIYANTO, ENIN.}

1998. Setengah Abad SeniGrafis Indonesia, Yasri, Jakarta Indonesia ISBN:

234330209.

\section{Internet:}

1. Art.with.mr sleuer. Com

2. https://id.wikipedia.org/wiki/Seni_grafis 